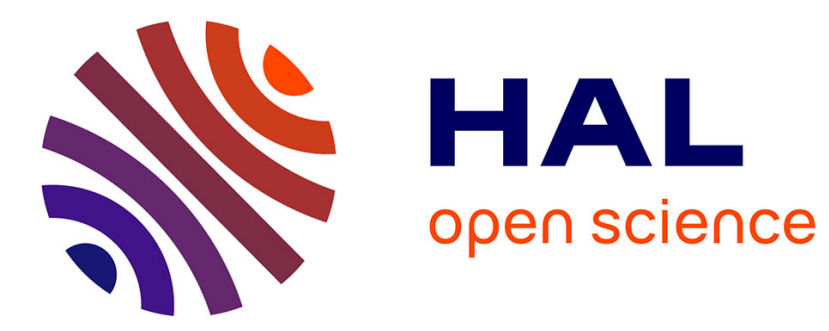

\title{
Communicating Science: Reform Model of the Gates Open Research Platform
}

\author{
Spaska Tarandova, Milena I Tsvetkova
}

\section{To cite this version:}

Spaska Tarandova, Milena I Tsvetkova. Communicating Science: Reform Model of the Gates Open Research Platform. Communication Management: Theory and Practice in the 21st Century, , pp.329343, 2020, E-ISBN-13: 978-619-7567-04-5; Print-ISBN-13: 978-619-7567-03-8. 10.2139/ssrn.3768850 . hal-03114506

\section{HAL Id: hal-03114506 https://hal.science/hal-03114506}

Submitted on 19 Jan 2021

HAL is a multi-disciplinary open access archive for the deposit and dissemination of scientific research documents, whether they are published or not. The documents may come from teaching and research institutions in France or abroad, or from public or private research centers.
L'archive ouverte pluridisciplinaire HAL, est destinée au dépôt et à la diffusion de documents scientifiques de niveau recherche, publiés ou non, émanant des établissements d'enseignement et de recherche français ou étrangers, des laboratoires publics ou privés.

\section{(1)(1) $\$(0)$}

Distributed under a Creative Commons Attribution - NonCommercial - ShareAlikel 4.0 


\title{
Communicating Science:
}

\section{Reform Model of the Gates Open Research Platform}

\author{
Spaska Tarandova, PhD Student \\ Sofia University St. Kliment Ohridski \\ Faculty of Journalism and Mass Communication \\ Sofia, Bulgaria \\ e-mail: tarandova@uni-sofia.bg \\ Milena Tsvetkova, Dr., Associate Professor \\ Sofia University St. Kliment Ohridski \\ Faculty of Journalism and Mass Communication \\ Sofia, Bulgaria \\ e-mail: milenaic@uni-sofia.bg
}

\begin{abstract}
Published Reference (Suggested Bibliographic Citation):
Tarandova, Spaska; Tsvetkova, Milena. Communicating Science: Reform Model of the Gates Open Research Platform. In: Communication Management: Theory and Practice in the 21st Century. 12th Central and Eastern European Communication and Media Conference CEECOM 2019. Sofia: Faculty of Journalism and Mass Communication at the Sofia University "St. Kliment Ohridski", 2020, pp. 329-343. Print-ISBN: 978-619-7567-03-8; E-ISBN: 978-619-7567-04-5.
\end{abstract}

Quoting from or reproduction of this paper is permitted when accompanied by the foregoing citation.

\begin{abstract}
:
The EU's scientific potential is increasingly flowing into the world of new scientific knowledge. The object of this paper is the communication interpretation of the Open Science policy, covering not only access and storage of scientific information and preservation of scientific information, but communication aspects also. Purpose of the study: Establish modern trends in the scientific ecosystem oriented towards facilitating the publication and communication of scientific results. Tasks of the study: Compare new solutions in science communication models in the most popular platforms, and explore what is the alternative to traditional scientific journals. Methodology/approach: The qualitative systematic review (qualitative evidence synthesis), scientific criticism of sociological surveys, methods of analytic and synthetic processing of primary and secondary resources, secondary data analysis and overview of scientific publications available in the libraries worldwide, have been used to obtain data about the impact of new EU solutions: the European Road Map for development of the European Research Area (ERA), the European Strategy Forum for Research Infrastructures (ESFRI), the Organization for Economic Cooperation and Development, etc. A comparative analysis of innovation in publishing platforms was conducted with special attention to the Bill and Melinda Gates Foundation's Gates Open Research platform. Results: The creators
\end{abstract}


of the Gates Open Research platform defend the view of the rapid and socially beneficial effect of new and publicly-accepted scientific knowledge. The cutting-edge solutions are: transfer power from the hands of editors to the hands of the authors; minimize barriers or gatekeepers on the path of the new scientific outcome for society; assessment of the research not in view of the venue of publication but on the basis of the intrinsic value of the completed study; minimize the funds invested in publishing and dissemination. Implications: The conclusions can be important in identifying technological and ideological regularities for optimizing the model of scientific publications and increasing the speed and visibility of any scientific news.

\section{Keywords:}

science communication, barriers to scientific communication, scientific ecosystem, open science, open refereeing process, open access publishing model, transparent publishing, author-led publication, research-centred platform, F1oooResearch, Plan S

\section{INTRODUCTION}

The past five years have witnessed more and more discussions in the EU about free access to scientific knowledge, in particular to results of publicly funded projects. If Europe wants to compete with the rest of the world, the regulations having a bearing on the access to scientific knowledge need to be liberalized, and the time required to provide free access to the latest publications, shortened. The feeling becomes ever more tangible that we are living in a time of "a war" for free access to scientific achievements. Representatives of various stakeholders ask questions, not only amongst themselves. More and more voices are heard in public, speaking about the price of scientific knowledge, its dissemination and re-use for new scientific results.

Over the past decade, it's been getting easier and easier to circumvent the paywalls and find free research online. One major reason: the active effort of the socalled science pirates working on-line for the cause of free access to, and use of, science. The most popular among them is Kazakh neurotechnology researcher and software developer Alexandra Elbakyan, also known as "Science's pirate queen". Her (illegal) website Sci-Hub sees more than 500,000 visitors daily (according to data from 25 April 2019'), and host more than 50 million academic reports.

At the start of 2019 we also received two unequivocal signals from global economic players: On 1 February 2019 Elon Musk opened the access to Tesla's patents

\footnotetext{
1 Sci-Hub. “Twitter@Sci_Hub”. 25.04.2019. Accessed June 16, 2019. https://twitter.com/sci_hub/status/1121397571539357697
} 
to be used for preserving the Earth ("to help save the Earth"”). Two months after that, on 3 April 2019, Toyota offered free access to 24,000 of its patents 3 .

The moods among scientists from all over the world, veering on frustration and disappointment, allow one to formulate the prediction that we are entering an era of scientific communism when knowledge will become free. In 2016, the Vox portal surveyed 270 scientists from different countries to determine what problems they believe are hindering modern science from developing dynamically. Based on the survey findings, seven main obstacles were formulated, among which the inaccessibility of scientific information was ranked on the fifth place: 1) Academia has a huge money problem; 2) Too many studies are poorly designed;3) Replicating results is crucial, and rare; 4) Peer-review is broken; 5) Too much science is locked behind paywalls; 6) Science is poorly communicated; 7) Life as a young academic is incredibly stressful. ${ }^{4}$

At this background, three groups of open access defenders stand out:

1) Librarians and science funders are playing hardball to negotiate lower subscription fees to scientific journals. Jeffrey K. MacKie-Mason, University Librarian and Chief Digital Scholarship Officer at the University of California, Berkeley, told Vox Media on 10 June 2019: "[The publishers] know it's going to happen. They just want to protect their profits and their business model as long as they can." 5

2) Scientists, increasingly, are realizing they don't need paywalled academic journals to act as gatekeepers any more. They are finding clever workarounds, making the services that journals provide free.

3) Open access crusaders, including science pirates, have created alternatives that free up journal articles and pressure publishers to expand the free access.

\footnotetext{
2 Simranpal Singh, "Tesla patents made public to save the world, reveals Elon Musk." Gizmo China, 01.02.2019. Accessed June 16, 2019. https:/www.gizmochina.com/2019/02/01/elon-musk-tesla-patents

3 Paul Ridden, "Toyota offers free access to over 20 years of electric vehicle patents." New Atlas, 3.04.2019. Accessed June 16, 2019, https://newatlas.com/toyota-royalty-free-patents-electric-vehicletechnology/59139

4 Julia Belluz, Brad Plumer, and Brian Resnick, "The 7 biggest problems facing science, according to 270 scientists." Vox, 07.09.2016. Accessed June 16, 2019, https://www.vox.com/2016/7/14/12016710/sciencechalleges-research-funding-peer-review-process

5 Brian Resnick, and Julia Belluz, "The war of free science: How librarians, pirates, and funders are liberating the world's academic research from paywalls." Vox, 10.07.2019. Accessed June 16, 2019, https://www.vox.com/the-highlight/2019/6/3/18271538/open-access-elsevier-california-sci-hubacademic-paywalls
} 


\section{BACKGROUND}

The political and economic context of the digital age connected with the creation, dissemination and use of scientific knowledge, is changing.

The Organization for Economic Co-operation and Development (OECD) was the first to announce a policy of Open Science in 2007. OECD's Digital Economy Papers ${ }^{6}$, published at the start of 2019, predict the appearance of a multitude of platforms and ecosystems offering goods, services, information, knowledge and new forms of intermediation for accessing and using them. The transformation in the economy calls into question the traditional thinking about how to organize and implement most effectively the economic and social activities. The digital ecosystems offer users comfort with a familiar interface that creates a sense of ease of use. The development of digital platforms raises questions related to equal access and market concentration. The OECD urges governing bodies to develop public platforms, either individually or in partnership with commercial platforms, to provide administrative and social services in the implementation of public policies.

In September 2018, the European Commission and the European Research Council (ERC), along with eleven national research funding organizations, announced the launch of Plan $S^{7}$ to make full and immediate Open Access to research publications. In 2019 the coalition was joined by funding organizations - 13 European research funding organizations and three charities (including the Bill \& Melinda Gates Foundation). The funders state they control around $€ 7.6$ billion of funds annually. This represents less than $1 \%$ of the nearly $\$ 2$ trillion global spend on R\&D. However, it is the academic papers arising from Plan S funders' R\&D activities that determine the effects on the scholarly publishing market. In this context, Plan $S$ funders have a more significant influence (Table 1$)^{8}$.

\footnotetext{
${ }^{6}$ OECD. Digital Economy Papers. Paris: OECD Publishing, no. 273, 2019. Accessed June 16, 2019, DOI: 10.1787/5adezbba-en.

7 Marc Schiltz, "Why Plan S." cOAlition S, 4.09.2018. Accessed June 16, 2019, https://www.coalitions.org/why-plan-s

8 Dan Pollock and Ann Michael, "Potential Impact of Plan S." Delta Think, 24.09.2018. Accessed June 16, 2019, https://deltathink.com/news-views-potential-impact-of-plan-s
} 
Table 1. Plan S - share of scholarly articles in context ${ }^{9}$

\begin{tabular}{|l|c|c|}
\hline \multicolumn{1}{|c|}{ Scholarly articles in 2017... } & $\begin{array}{c}\text { Shares of Global } \\
\text { Research Articles }\end{array}$ & $\begin{array}{c}\text { Share of Global } \\
\text { OA Output }\end{array}$ \\
\hline Plan S Funders Share of Global Output & $3.3 \%$ & $4.1 \%$ \\
\hline Plan S Countries Share of Global Output & $15 \%$ & $18.4 \%$ \\
\hline Plan S Funders Share of their Countries Output & $22 \%$ & n/a \\
\hline EU proportion of Global Output & $26 \%$ & $32.8 \%$ \\
\hline $\begin{array}{l}\text { Plan S Funders' Share of Global Output including } \\
\text { equivalent level of funder coverage from Germany }\end{array}$ & $3.9 \%$ & $4.9 \%$ \\
\hline
\end{tabular}

The consortium around Plan S, called cOAlition $\mathrm{S}^{10}$, works with Digital Science $^{11}$ and combines the latter's data with data from Delta Think's Open Access Data \& Analytics Tool ${ }^{12}$, which makes it possible to determine, approximately, the ratio in the research production. Plan S funders account for roughly 3.3\% of articles published globally. These include all articles where a Plan S funder is involved, even as part of a jointly-funded or multi-author project. Although many of the Plan S funders are national, they account for just over one fifth of their respective countries' publication output. Also, as Plan S funders are OA advocates, they account for a higher than average share of OA output. Plan S principles are also consistent with other OAadvocacy countries (Germany), several institutions (University of California), funders (Bill \& Melinda Gates Foundation), and with the broader EU principles of a move to OA by 2020. It is reasonable to posit that Plan $\mathrm{S}$ will gain additional support from a variety of OA stakeholders. One such example is Germany. Its absence from inclusion may well be a matter of the timing due to its on-going publisher negotiations, rather than differences in long-term position.

\footnotetext{
9 Dan Pollock and Ann Michael, "Potential Impact of Plan S." Delta Think, 24.09.2018. Accessed June 16, 2019, https://deltathink.com/news-views-potential-impact-of-plan-s

${ }^{10}$ COAlition S. Brussels, Belgium: Science Europe, 2019. Accessed June 16, 2019, https://www.coalition-s.org

${ }^{11}$ Digital Science. London: Digital Science \& Research Ltd, 2019. Accessed June 16, 2019, https:/www.digitalscience.com

${ }^{12}$ Delta Think Open Access Data \& Analytics Tool (OA DAT). Delta Think, 2019. Accessed June 16, 2019, https://deltathink.com/open-access/oa-data-analytics-tool
} 


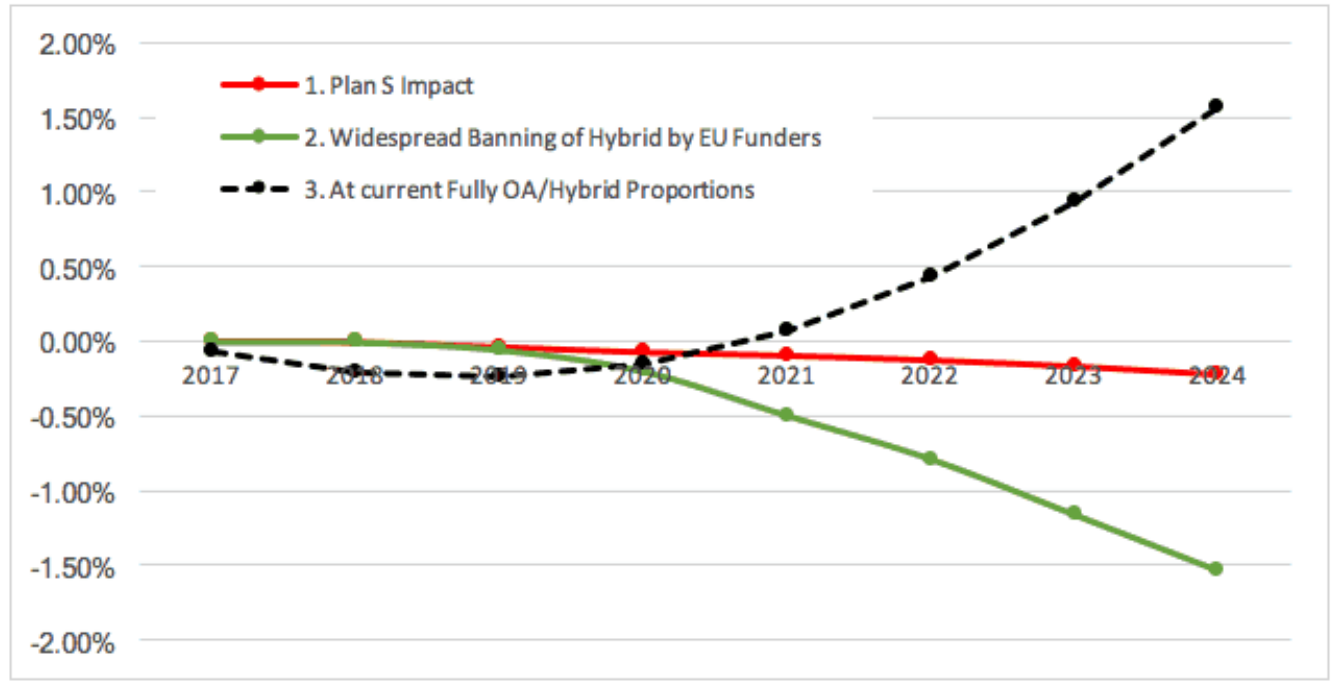

Figure 1. Change in market value of Plan S uptake scenarios compared with current projections $^{13}$

Plan S includes a number of revolutionary principles that impact the market. Its preamble and principles mention banning publication in hybrid journals, requiring CC-BY licenses (Creative Commons Attribution 2.0) to be held by the author, instituting caps on APC (Article processing charge) funding, and the cOAlition S view on using the Journal Impact Factor for quality assessment and on the ban of the hybrid model. Broad advocacy exists in respect of the widespread banning of the hybrid model by EU funders covering OA output of all EU countries, among them of high OA-uptake countries, such as the UK, Austria, the Netherlands, and Sweden. Reactions to Plan S have ranged from delighting OA advocates, to suggesting that this is simply a part of the on-going discussion about $\mathrm{OA}$, to responses from the mainstream scholarly publishing community urging for more detailed consideration of the complexities of the scholarly publishing market, to concerns from some researchers that it will deprive them of quality journal venues and of international collaborative opportunities.

The planned launch of Plan S, with the primary goal of opening access to publicly funded research in the European Union as of 1 January 2020, was postponed to

\footnotetext{
${ }^{13}$ Dan Pollock and Ann Michael. "Potential Impact of Plan S." Delta Think, 24.09.2018. Accessed June 16, 2019, https://deltathink.com/news-views-potential-impact-of-plan-s
} 
$2021^{14}$. Following consultations with academic libraries, publishers and researchers, cOAlition S announced that until 2021, eased requirements will apply ${ }^{15}$ :

1) cOAlition $S$ will not place a cap on the cost of publishing a paper in an open-access journal. But they say journals must be transparent about publishing costs.

2) cOAlition $S$ changed the rules concerning hybrid titles and offered "transformative agreements", which give these partly paywalled journals a route to becoming open access.

3) cOAlition $S$ will ignore the prestige of journals when making funding decisions.

4) In some cases, researchers will be able to publish work under more restrictive open licences, when approved by cOAlition $\mathrm{S}$.

The reasons for the postponement can be found in two directions - in the resistance of the publishing community whose actions are increasingly in the direction of protecting their own profit, rather than protecting the quality of research and the interests of the authors, or related to the protection of the interests of researchers, their copyright and the quality of research output. It can only be noted that the use of hybrid journals is a temporary measure to full open access. Plan S is intended to accelerate the changes in this direction. Its small core of funders can have a significant impact in the future when access to research publications will increasingly be through open science on-line platforms.

\section{METHODOLOGY}

Hypothesis: Revolutionary changes in the organization and functioning of academic journals are looming, and the model of scholarly publishing will be changed for good.

Object: open-access resources for research communication

Subject: the positive changes for academic authors and their publications in the contest of the digital transformation

\footnotetext{
${ }^{14}$ cOAlition S, Plan S: Principles and Implementation. Brussels, Belgium: Science Europe, 2019. Accessed June 16, 2019, https://www.coalition-s.org/principles-and-implementation

${ }^{15}$ Holly Else, "Radical open-access plan could spell end to journal subscriptions." Nature 561, (2018): 17-18. Accessed June 16, 2019, DOI: 10.1038/d41586-018-06178-7.
} 
The study focused on the development of the view of a rapid-effect socially beneficial science based on an open-access policy, and addressed four overarching research questions:

1. What changes are expected at the EU level in respect of access to publiclyfunded scientific output produced by the research effort of international teams?

2. Are the questions about the purpose of scientific achievements primarily of moral and philosophical essence, or are they predominantly related to economic and business interests?

3. Are the editorial teams of scientific journals threatened by the two ongoing debates - about the effectiveness of open peer reviews and about ignoring the significance of the impact factor (IF and IR) of their publications?

The qualitative systematic review (qualitative evidence synthesis), the methods of the analytic and synthetic processing of primary and secondary resources, secondary data analysis and overview of scientific publications available in the libraries worldwide, were used to obtain data about the impact of new EU solutions: the European Road Map for development of European Research Area (ERA), the European Strategy Forum for Research Infrastructures (ESFRI), the Organization for Economic Cooperation and Development, etc. The analysis of innovation in publishing platforms was conducted with special attention to the Bill and Melinda Gates Foundation's platform Gates Open Research.

\section{OBJECT OF THE RESEARCH: GATES OPEN RESEARCH PLATFORM}

The Bill \& Melinda Gates Foundation was among the first open-science funders in the world. As far back as in 2013 Gates supported the just starting Berlinbased ResearchGate, the most popular and free networking website for scientists, with funding to the amount of USD 35 million $^{16}$.

In November 2014, the Bill and Melinda Gates Foundation changed the rules for research funding by putting in place an open-data policy. Researchers could

\footnotetext{
${ }^{16}$ Bill \& Melinda Gates Foundation. Seattle, WA, 2019. Accessed June 16, 2019. https://www.gatesfoundation.org/What-We-Do
} 
publish in subscription journals but had to guarantee that after 12 months their papers be made freely available ${ }^{17}$.

As of 1 January 2017, after a so-called "grace period", the Foundation's rules were changed and publishing with closed access is no longer allowed. "Personally, I applaud the Gates Foundation for taking this stance," says Simon Hay, a Gates-funded researcher who is director of geospatial science at the Institute for Health Metrics and Evaluation in Seattle, Washington. "The overwhelming majority of my colleagues in global health and fellow Gates grantees with whom I have chatted are highly supportive of these developments," he says. ${ }^{18}$

The Foundation requires the publication of articles under the free Creative Commons Attribution license which enables dissemination and processing of material subject to designation of authorship.

Scientists who do research funded by the Bill \& Melinda Gates Foundation are not allowed to publish papers about that work in journals that include Nature, Science, the New England Journal of Medicine (NEJM) and the Proceedings of the National Academy of Sciences (PNAS). This is due to the fact that the charity requires from grant recipients to publish open-access research, whereas the journals in question do not offer this kind of open-access publishing.

A spokesperson for Nature's publisher, Springer Nature, said that most Springer Nature journals do comply with the Gates Foundation policies, but a "small number", including Nature and some Nature-branded research titles, do not. "At the moment we believe the subscription model is still the best way to provide sustainable and widespread access to journals with low acceptance rates such as Nature and the Nature-branded research and reviews titles," the spokesperson added. ${ }^{19}$

\footnotetext{
17 Richard Van Noorden, "Gates Foundation announces world's strongest policy on open access research." Nature, 21.11.2014. Accessed June 16, 2019, http://blogs.nature.com/news/2014/11/gates-foundationannounces-worlds-strongest-policy-on-open-access-research.html

${ }^{18}$ Richard Van Noorden, "Science journals end open-access trial with Gates Foundation." Nature, 13.07.2018. Accessed June 16, 2019, http://www.nature.com/articles/d41586-018-05729-2

${ }^{19}$ Richard Van Noorden, "Gates Foundation research can't be published in top journals." Nature 541, (17.01.2017): 270. Accessed June 16, 2019, http://www.nature.com/news/gates-foundation-researchcan-t-be-published-in-top-journals-1.21299
} 


\section{RESULTS}

The Gates Open Research is the newest publication medium that researchers supported by the Gates Foundation can use in order to disseminate their data in a way which is fully compliant with their open access policy. The website was launched on 1 January 2017 as a platform for rapid publication by researchers, with transparent peer review $^{20}$. Publications with closed/paid access are not admitted as of this date.

Gates Open Research is based on F1oooResearch's format ${ }^{21}$. F10oo is an abbreviation for the Faculty of 1000 - a cadre of experts who provide peer review and recommendations as needed. F1oooResearch is an open science post-publication peer review platform. The Bill and Melinda Gates Foundation is the second funding body to partner with F1ooo to generate an open-access academic publishing platform (the first was the Wellcome Trust).

The Gates Open Research platform advocates the view of the rapid and beneficial societal impact of the new and publicly accepted research. Essentially, the entire work in the platform is carried out by the team of FroooResearch, and the Foundation covers the publishing costs. The publication of an article up to 1,ooo words costs $\$ 150$, from 1,000 to 2,500 words - $\$ 500$, and more than 2,500 words, $\$ 1,000$. The Wellcome Trust charitable foundation works on the same principle. In November 2016 the charity signed an agreement with F1oooResearch and has since published about 50 research articles for Wellcome Open Research. On average, an article costs $\$ 990$ to the charity, the manuscript reaches the website within seven days and is refereed in the course of one month.

Gates Open Research gives authors significantly more control than normally given to them by a traditional publication model. Authors can decide what and when to publish, including replication studies and negative results. Authors will also be able to suggest reviewers for their paper or choose from a list of suggested reviewers. This is the essence of the author-led open peer-review model. The refereeing process takes 14 days at the most (Figure 2). Once submitted, the article has to pass basic editorial checks by the F1ooo faculty prior to publication. This final process usually takes seven

\footnotetext{
${ }^{20}$ Gates Open Research. London: Bill \& Melinda Gates Foundation, F100o Research Ltd., 2019. Accessed June 16, 2019, https://gatesopenresearch.org

${ }^{21}$ F100oResearch. London: Science Navigation Group, 2019. Accessed June 16, 2019, https://f10ooresearch.com
} 
days (Figure 3). An important fact is that the grantees of the Bill \& Melinda Gates Foundation each year publish 2,000-2,500 papers in the area of healthcare and education.

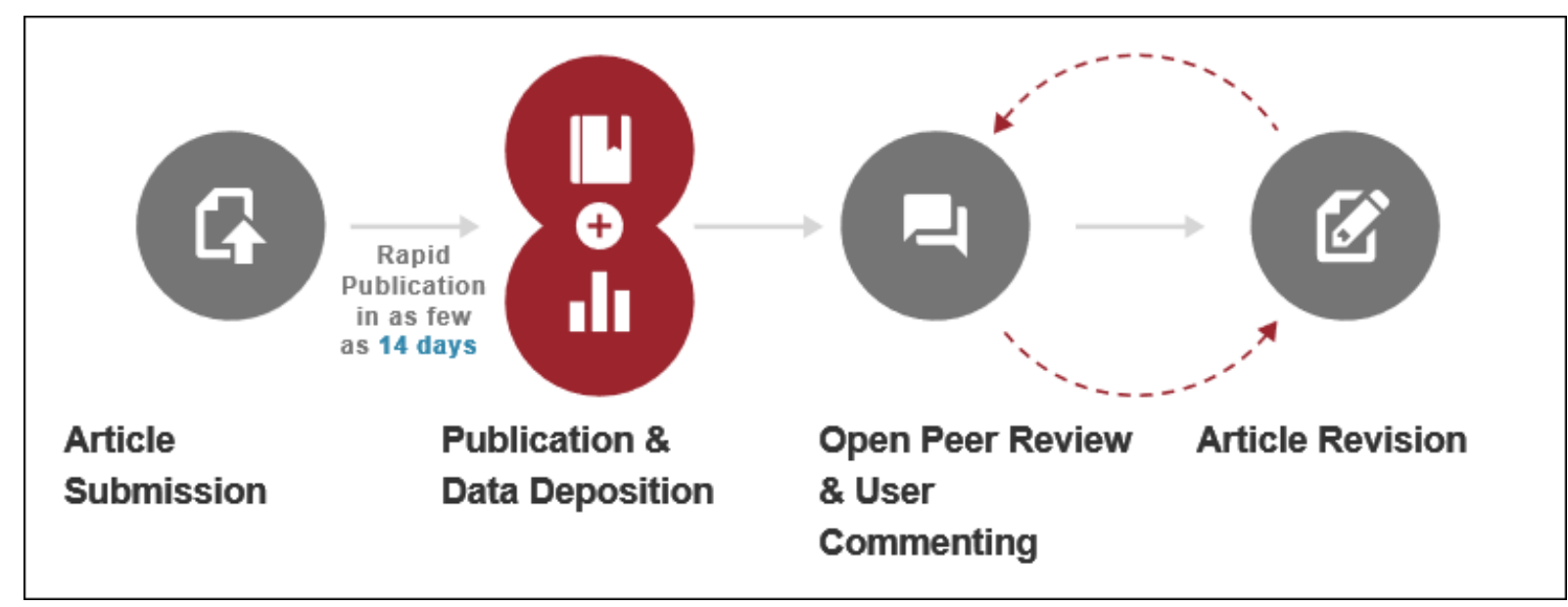

Figure 2. The length of the refereeing process: 14 days ${ }^{22}$

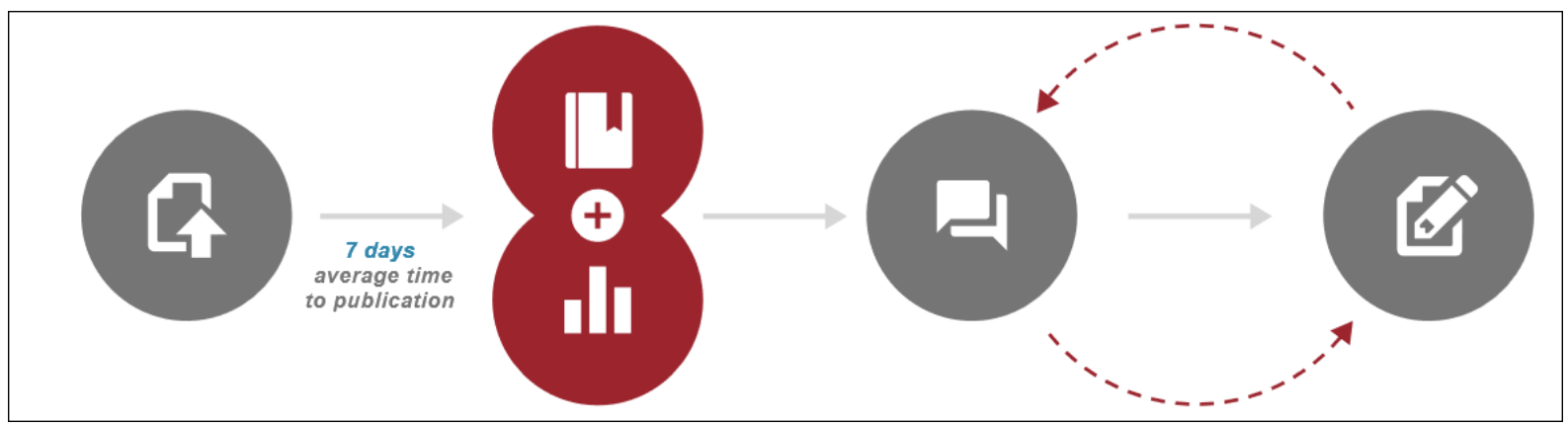

Figure 3. The length of the publishing process for articles: 7 days ${ }^{23}$

To recap, below we offer a summary of the most important characteristics of the new model of intermediation in science legitimized by the Gates Open Research:

Benefits for researchers: Enables authors, not editors, to decide when to make their research available. Authors suggest peer reviewers and control the process. All types of research can be published rapidly: articles, data sets, null results, protocols, case reports, incremental findings, etc.

\footnotetext{
${ }^{22}$ Gates Open Research, Guidelines for Article Reviewers. London: Bill \& Melinda Gates Foundation, F1000 Research Ltd., 2019. Accessed June 16, 2019, https://gatesopenresearch.org/for-referees/guidelines

${ }^{23}$ Gates Open Research, How it Works. London: Bill \& Melinda Gates Foundation, F100o Research Ltd., 2019. Accessed June 16, 2019, https://gatesopenresearch.org/about
} 
Benefits for research: Shifts the way research and researchers are evaluated. Moves away from journal-based ranging towards direct assessment of individual outputs. Supports research assessment based on the intrinsic value of the research, not the venue of publication.

Benefits for society: Reduces the barrier to collaborative research through data sharing, transparency and attribution. Reduces research waste and helps to remove the bias in our understanding of research. Enables others to build upon new ideas right away, wherever and whoever they are.

The Gates Foundation is dedicated to the belief that all lives have equal value and everyone deserves the opportunity to lead a healthy and productive life. To solve the challenges of the 21st century, we must accelerate open access to high-quality research on health, education, and economic development. Gates Open Research is designed to ensure that the research we fund can be of immediate benefit to society.

If we are to summarize the contribution of the platform, it is found in the following:

\ a shift from author-centred to research-centred platform;

$\otimes$ transfer power from the hands of the editors to the hands of the authors;

$凶$ minimize barriers or gatekeepers on the path of the new scientific outcome for society;

凶 transparent peer-review of research;

$\mathbf{x}$ assessment of the research not in view of the venue of publication but on the basis of the intrinsic value of the completed study;

冈 minimizing the funds invested in publishing and dissemination.

\section{CONCLUSION}

After 2017, the landscape of scholarly publishing is much different, thanks in large part to non-governmental funds that already mandate open access. Large foundations such as Ford, Gates and Hewlett have adopted strong open-access policies that require research to be not only publicly available, but also licensed to allow republishing and re-use by anyone. The world's second-largest charitable foundation, the Wellcome Trust, also offers free access to the scientific output of everyone who receives financial support from it. But if the publisher does not allow them to publish 
for free access, the Wellcome Trust allows such articles to be embargoed for up to six months.

The circumstances that were examined indicate that revolutionary changes in the organization and functioning of academic journals are looming, and the model of scholarly publishing will be changed for good:

\The barriers and gatekeepers on the path of new scientific outcomes to society will be reduced influenced by the tendency of disintermediation in the financial sector.

冈 The funds invested in scientific communication will be streamlined.

\ The benefits of open refereeing will be advanced

冈 The future models of communicating science will centre on new knowledge and new scientific outcomes, and not on the author or the venue of publication (the name of the journal).

冈 The platforms for scientific knowledge creation and sharing will shift from being researcher-centric platforms to being research-centric platforms, hand in hand with the shift of the media environment from an "economy of attention" towards an "ecology of attention"

EU's research potential is increasingly entering a research ecosystem of decommodification and decapitalization. It may well be that the driving forces behind a more radical and urgent change are entrepreneurs and philanthropists such as Bill Gates and Elon Musk.

Universality is a fundamental principle of science. Only results that can be discussed, challenged, and reproduced by others qualify as scientific. The moral solution is open access. What is needed is to find the proper legal framework for a fair distribution of the benefits between science and society. "Knowledge is not simply another commodity. On the contrary. Knowledge is never used up. It increases by diffusion and grows by dispersion”, Daniel Boorstin, U.S. Library of Congress Director (1975-1987), says.

\footnotetext{
${ }^{24}$ Yves Citton, The Ecology of Attention (Cambridge: John Wiley \& Sons, 2017), 28.
} 


\section{BIBLIOGRAPHY}

Belluz, Julia, Brad Plumer, and Brian Resnick. "The 7 biggest problems facing science, according to 270 scientists." Vox, 07.09.2016. Accessed June 16, 2019. https://www.vox.com/2016/7/14/12016710/science-challeges-research-funding-peer-reviewprocess

Bill \& Melinda Gates Foundation. "What We Do." Seattle, 2019. Accessed June 16, 2019. https://www.gatesfoundation.org/What-We-Do

Citton, Yves. The Ecology of Attention. Cambridge: John Wiley \& Sons, 2017.

cOAlition S, Plan S: Principles and Implementation. Brussels, Belgium: Science Europe, 2019. Accessed June 16, 2019. https://www.coalition-s.org/principles-and-implementation

cOAlition S. "About." Brussels, Belgium: Science Europe, 2019. Accessed June 16, 2019. https://www.coalition-s.org

Delta Think Open Access Data \& Analytics Tool (OA DAT). "About." Delta Think, Philadelphia, 2019. Accessed June 16, 2019, https://deltathink.com/open-access/oa-dataanalytics-tool

Digital Science. “About.” London: Digital Science \& Research Ltd, 2019. Accessed June 16, 2019. https://www.digital-science.com

Else, Holly. "Radical open-access plan could spell end to journal subscriptions." Nature 561, (2018): 17-18. Accessed June 16, 2019. DOI: 10.1038/d41586-018-06178-7.

F1oooResearch. “About.” London: Science Navigation Group, 2019. Accessed June 16, 2019. https://fioooresearch.com

Gates Open Research. “About.” London: Bill \& Melinda Gates Foundation, F1ooo Research Ltd., 2019. Accessed June 16, 2019. https://gatesopenresearch.org

Gates Open Research. Guidelines for Article Reviewers. London: Bill \& Melinda Gates Foundation, F100o Research Ltd., 2019. Accessed June 16, 2019. https://gatesopenresearch.org/for-referees/guidelines

Gates Open Research. How it Works. London: Bill \& Melinda Gates Foundation, F1ooo Research Ltd., 2019. Accessed June 16, 2019. https://gatesopenresearch.org/about

OECD. Digital Economy Papers. Paris: OECD Publishing, no. 273, 2019. Accessed June 16, 2019. DOI: 10.1787/5ade2bba-en.

Pollock, Dan and Ann Michael. "Potential Impact of Plan S." Delta Think, 24.09.2018. Accessed June 16, 2019. https://deltathink.com/news-views-potential-impact-of-plan-s

Resnick, Brian and Julia Belluz. "The war of free science: How librarians, pirates, and funders are liberating the world's academic research from paywalls." Vox, 10.07.2019. Accessed June 16, 2019. https://www.vox.com/the-highlight/2019/6/3/18271538/open-access-elseviercalifornia-sci-hub-academic-paywalls

Ridden, Paul. "Toyota offers free access to over 20 years of electric vehicle patents." New Atlas, 3.04.2019. Accessed June 16, 2019. https://newatlas.com/toyota-royalty-free-patents-electricvehicle-technology/59139

Schiltz, Marc. Why Plan S. cOAlition S, 4.09.2018. Accessed June 16, 2019. https://www.coalition-s.org/why-plan-s

Sci-Hub. “Twitter@Sci_Hub.” 25.04.2019. Accessed June 16, 2019. https://twitter.com/sci hub/status/1121397571539357697 
Singh, Simranpal. "Tesla patents made public to save the world, reveals Elon Musk." Gizmo China, 01.02.2019. Accessed June 16, 2019. https://www.gizmochina.com/2019/o2/o1/elonmusk-tesla-patents

Van Noorden, Richard. "Gates Foundation announces world's strongest policy on open access research.” Nature, 21.11.2014. Accessed June 16, 2019. http://blogs.nature.com/news/2014/11/gates-foundation-announces-worlds-strongestpolicy-on-open-access-research.html

Van Noorden, Richard. "Gates Foundation research can't be published in top journals." Nature 541, (17.01.2017): 270. Accessed June 16, 2019. http://www.nature.com/news/gatesfoundation-research-can-t-be-published-in-top-journals-1.21299

Van Noorden, Richard. "Science journals end open-access trial with Gates Foundation." Nature, 13.07.2018. Accessed June 16, 2019. http://www.nature.com/articles/d41586-01805729-2 